\title{
Uji Resistensi 22 Plasma Nutfah Kapas terhadap Hama Utama pada Fase Generatif
}

\section{Resistance Test of 22 Cotton Germplasms to Main Pests in the Generative Phase}

\author{
Dedi Supriyatdi, Riki Rudianto*, Mirodi Syofian, Jakty Kesuma \\ Department of Plantation Plant Cultivation, Politeknik Negeri Lampung, Bandar Lampung, Indonesia \\ ${ }^{*}$ Corresponding author: riky28rudianto@gmail.com
}

Received: November 9, 2019; Accepted: March 30, 2020; Published: April 1, 2020

\begin{abstract}
The produced of cottons fiber widely used as a raw material for the textile industry in Indonesia. However, many cotton plant are attacked by pests such as Dysdercus cingulatus, Bemissia tabaci, Spodoptera litura and Antractomorpa crenulata so that cotton production is still low. There are 3 categories mechanism of plant resistance to pest attacks, namely antixenosis, tolerance, and antibiosis. This research aimed to test the resistance of cotton plants to pest attacks. This research was conducted in experimental field Politeknik Negeri Lampung from May to November 2018. The method used was randomized block design consisting of 22 treatments and 2 replications with each treatment consisting of 5 plants, so that 220 plants were obtained. Observation data were managed through analysis of variance (Anova) if the mean values were different then proceed with the $5 \%$ Least Sigificance Difference test. The results showed that FDH 834 cotton germplasm was resistant to leaf damage but susceptible to stem damage in the generative phase and SA 2465 cotton germplasm was resistant to fruit borer pests.
\end{abstract}

Key words: cotton damage, damage intensity, varieties

Cite this as: Supriyatdi, D., Rudianto, R., Syofian, M., \& Kesuma, J. (2020). Uji Resistensi 22 Plasma Nutfah Kapas terhadap Hama Utama pada Fase Generatif. Agrosains : Jurnal Penelitian Agronomi 22(1): 21-24. DOI: http://dx.doi.org/10.20961/agsjpa.v22i1.35535

\section{PENDAHULUAN}

Kapas (Gossypium sp.) merupakan tanaman perdu semusim yang menjadi salah satu andalan sub sektor perkebunan. Serat yang dihasilkannya banyak dimanfaatkan sebagai bahan baku dalam industri tekstil dan produk tekstil di Indonesia, tetapi kemajuan industri tersebut belum sepenuhnya mendapat dukungan dalam penyediaan bahan baku. Produksi serat kapas dalam negeri hanya berkisar 1.600-2.500 ton (kurang dari 0,5\% kebutuhan nasional), sehingga sebagian besar diperoleh melalui impor. Produksi kapas di Indonesia sangat rendah yaitu berkisar 1,871 ton, dalam 1 ha menghasilkan sebanyak $288 \mathrm{~kg}$ (Kementerian Pertanian, 2014). Berbanding terbalik dengan negara-negara lain memiliki hasil 5 kali lipat lebih dari produksi Indonesia seperti Pakistan dalam 1 tahun dapat menghasilkan produksi kapas sebanyak 1.689 Australia $1.380 \mathrm{~kg} \cdot \mathrm{ha}^{-1}$ dan Cina $1.380 \mathrm{~kg} \cdot \mathrm{ha}^{-1}$ (Johnson et al. 2014). Kerugian hasil panen kapas yang disebabkan serangan hama atau penyakit di Indonesia berkisar $40-50 \%$. Hama yang menyerang berupa Dysdercus cingulatus, kutu kebul (Bemisia tabaci), Ulat grayak (Spodoptera litura), kutu daun (Aphis gossypii) dan belalang hijau (Antractomorpa crenulata). Hama Bemisia tabaci pada fase nimfa dan serangga dewasa menyerang dengan cara mengisap cairan dari permukaan daun dibagian bawah daun. Daun yang terserang memiliki ciri-ciri daun berwarna kuning, belang-belang atau loreng, pertumbuhan pada tanaman lambat, dan struktur tanaman menjadi lemah. Serangan yang besar dapat menyebatkan kematian pada tanaman kapas (Kasno et al. 2015).

Aphis gossypii merupakan hama yang menyerang tanaman kapas dengan cara mengisap cairan sel daun sehingga daun berkerut atau menggulung, layu kemudian gugur (Dewi, 2014). Hama ini sangat berpengaruh dalam menurun produksi kapas jika tidak dikendalikan. Hama ini menyerang tanaman kapas sepanjang tanaman kapas tersebut hidup. Ketahanan tanaman kapas terhadap hama penggerek buah berhubungan dengan kandungan gosipol tanin dalam kapas (Harsanti, 2016). Senyawa gosipol merupakan senyawa toksin dapat mengurangi berat badan larva S. litura (Hagenbucher et al. 2017). Banyaknya trikoma pada daun dan batang juga dapat mengurangi hama dalam peletakan telur serta menyerang tanaman kapas. Menurut Sahid (2001) pada musim hujan dapat menyebabkan kerusakan karena terjadi ledakan hama pada tanaman kapas. 
Penelitian dilakukan bertujuan untuk menguji resistensi 22 plasma nutfah kapas (Gossypium sp.) terhadap serangan hama.

\section{BAHAN DAN METODE}

Penelitian ini telah dilaksanakan di Lahan Percobaan Politeknik Negeri Lampung pada bulan Mei sampai November 2018. Bahan yang digunakan dalam penelitian ini adalah benih 22 plasma nutfah kapas, pupuk NPK, air, top soil, pupuk kandang dan karbofuran. Alat yang digunakan selama penelitian ini adalah cangkul, cangkul kecil, gembor, timbangan digital, mikroskop, jangka sorong, polybag ukuran 25 $\mathrm{cm} \times 40 \mathrm{~cm}$, cutter, gunting, paranet, plastik UV, bambu dan naungan.

Penelitian ini menggunakan Rancangan Acak Kelompok (RAK) diulang 2 kali dengan menggunakan 22 plasma nutfah sebagai perlakuan sehingga terdapat 44 satuan percobaan. Setiap perlakuan ditanam 5 tanaman sehingga terdapat 220 tanaman. Penelitian ini menggunakan pola tanam monokultur dengan populasi 220 kapas memiliki genjah yang cepat dalam 1 ha dapat ditanam dengan populasi tanaman berumur sedang sekitar 40.000 tanaman. Populasi tanaman/ha tersebut ditentukan oleh jarak tanam dan faktor fisik lingkungan yang tanamannya berakibat mempengaruhi tinggi rendahnya produksi kapas per/ha. Kapas yang ditanam memiliki 22 varietas sebagai pembanding yang ditanam musim kering untuk mencari tanaman yang produksinya tinggi dan tahan terhadap hama.

Pengamatan dilakukan pada saat tanaman kapas memasuki fase generatif. Variabel yang diamati adalah intensitas kerusakan daun, intensitas kerusakan batang, kerusakan boll dan bobot boll. Data hasil pengamatan diolah melalui analisis varian (Anova), jika nilai rata-rata berbeda nyata dilanjutkan uji Beda Nyata Terkecil (BNT) 5\%. Kerusakan boll dengan menggunakan metode skoring jika boll tidak rusak memiliki nilai 1 dan jika rusak sebagian memiliki nilai 3 dan jika rusak semua nilai 5 . Bobot diamati dengan cara menimbangnya.

Rumus intensitas kerusakan daun, bunga dan batang yaitu:

$$
\text { I: } \frac{a}{b} \times 100 \%
$$

Keterangan: I: intensitas kerusakan (\%), a: jumlah bagian tanaman yang rusak, b: jumlah seluruh tanaman yang diamati.

\section{HASIL DAN PEMBAHASAN \\ Kerusakan Batang pada Fase Generatif}

Perlakuan plasma nutfah kapas tidak memberikan pengaruh nyata terhadap kerusakan batang. Jika terjadi kerusakan batang akan sulit mengembalikan/memulihkan batang yang terkena hama tersebut. Pada panen tanaman kapas sangat banyak terserang hama terutama pada buah sehingga memungkin terjadinya kegagalan panen.

Menurut Harsanti (2006), unsur-unsur iklim yang sangat menuntukan pertumbuhan tanaman kapas seperti curah hujan, suhu udara, radiasi surya, kelembapan dan kecepatan angin. Iklim juga mempengaruhi dalam proses hama dalam merusak tanaman kapas. Seperti oleh belalang (Antractomorpa crenulata) apa bila banyak hujan dan awan maka perkembangan nimfa belalang akan terhambat, dan hujan lebat akan membunuh nimfa belalang. Telur belalang akan menetas sekitar 5 - 7 bulan (Pracaya, 1999). Perkembangbiakan belalang terjadi pada saat musim hujan dan suhu antara $20-27^{\circ} \mathrm{C}$. Hal ini disebabkan pada kondisi tersebut gulma juga mengalami pertumbuhan dan menjadi inang bagi belalang. Lingkungan juga sangat mempengaruhi perkembangan hama. Ordo lepidoptera pada fase nimfa yang merusak dengan memakan daun seperti ulat grayak (Spodoptera litura) serangan berat terjadi musim hujan di lahan kering dan musim kemarau di lahan sawah (Tengkano dan Suharsono, 2005).

\section{Intensitas Kerusakan Daun pada Fase Generatif}

Perlakuan plasma nutfah kapas memberikan pengaruh nyata terhadap intensitas kerusakan daun. Resistensi tanaman sangat erat kaitanya dengan pertahanan secara fisiologis dan morfologis pada tanaman kapas dalam menghambat serangan hama pada kapas. Kapas yang paling rentan terhadap serangan hama yaitu plasma nutfah Chris 666 dan kapas yang memiliki ketahanan yang baik atau toleran dimiliki oleh plasma nutfah FDH 834 (Tabel 1).

Tabel 1. Indeks kerusakan daun pada Fase Generatif

\begin{tabular}{|c|c|}
\hline Perlakuan & Rataan \\
\hline FDH 834 & $7,965^{a}$ \\
\hline Marvin 425 & $20,636 a b$ \\
\hline Kanesia 11 & $22,005^{a b c}$ \\
\hline Chris 670 & $22,961 \mathrm{abc}$ \\
\hline Kanesia 14 & $25,415 a b c$ \\
\hline Chris 324 & $31,260 \mathrm{bcd}$ \\
\hline Chris 665 & 31,550 bcde \\
\hline SA 2467 & 31,965 bcde \\
\hline Chris 668 & 32,263 bcde \\
\hline Kanesia 18 & 32,339 bcde \\
\hline Kanesia 19 & 34,430 bcde \\
\hline Chris 664 & 35,035 bcde \\
\hline SA 2465 & 35,762 bcde \\
\hline Chris 669 & 37,278 bcde \\
\hline Kanesia 12 & 38,861 bcde \\
\hline Kanesia 16 & 39,640 bcde \\
\hline Chris 667 & 40,351 cde \\
\hline Kanesia 20 & $41,108 \mathrm{cde}$ \\
\hline Kanesia 17 & $45,255^{\mathrm{de}}$ \\
\hline Kanesia 15 & 46,709 de \\
\hline Kanesia 13 & 49,647 de \\
\hline Chris 666 & $50,867^{e}$ \\
\hline
\end{tabular}

Keterangan: Angka pada kolom yang diikuti dengan huruf yang sama menunjukkan tidak berbeda nyata (non significant) pada Uji BNT 5\%

Daun kapas banyak yang rusak diduga disebabkan oleh ulat grayak (Spodoptera litura). Ulat grayak muda (instar 2-3) merusak daun dengan dengan meninggalkan sisa-sisa empidermis dan tulang daun sedangkan pada (instar 5-6) merusak 
daun dengan terbentuknya lubang-lubang daun yang ukuranya cukup besar. Panjang pendeknya bulu-bulu (trikoma) dan tebal tipisnya empidermis mempengaruhi intensitas daya makan larva Spodoptera litura dan gangguan dalam pergerakan Selain itu juga terdapat hama bapak pucung (Dysdercus cingulatus) pada daun tanaman kapas.

Hama ini menyerang pada daun dengan cara menusuk dan mengisap cairan daun tersebut hingga akhirnya mengering (Natasa et al. 2016). Kutu kebul (Bemissia tabaci) banyak terdapat di bawah bagian daun, hama ini menyerang daun dengan cara menusuk dan mengisap cairan daun yang muda. Intensitas cahaya adalah salah satu faktor lingkungan yang mempengaruhi luas permukaan daun. Semakin luas permukaan daun maka jumlah trikoma semakin banyak (Fahn, 1990).

Hama ini menyerang pada daun dengan cara menusuk dan mengisap cairan daun tersebut hingga akhirnya mengering (Natasa et al. 2016). Kutu kebul (Bemisia tabaci) banyak terdapat di bawah bagian daun, hama ini menyerang daun dengan cara menusuk dan mengisap cairan daun yang muda. Intensitas cahaya adalah salah satu faktor lingkungan yang mempengaruhi luas permukaan daun, semakin luas permukaan daun maka jumlah trikoma semakin banyak (Fahn, 1990).

\section{Kerusakan Bunga pada Fase Generatif}

Perlakuan plasma nutfah kapas tidak memberikan pengaruh nyata terhadap kerusakan bunga. Pada fase generatif tanaman sangat membutuhkan air yang cukup untuk memproduksi bunga dan bakal buah, saat fase tersebut terjadi pada bulan juli dimana bulan tersebut memiliki curah hujan rata-rata perbulan $2 \mathrm{~mm}$. Perkembangan buah kapas tidak terjadi secara serempak melainkan bertahap setiap plasma nutfahnya. Banyak hama yang menghendaki keadaan yang lembab untuk berkembangbiak. Maka kemungkinan kerusakan bunga pada penelitian ini sangatlah menim kerusakan bunga. Saat berbunga dan berbuah terjadi bulan Juli sangatnya minim curah hujan tersebut karena saat berbunga dan berbuah kapas memerlukan air yang cukup dalam pembentukan bunga dan buah.

\section{Kerusakan Boll pada Fase Generatif}

Perlakuan plasma nutfah kapas memberikan pengaruh nyata terhadap kerusakan boll. Pertahanan dalam bentuk fisologis yang menyebabkan tanaman tersebut tahan terhadap serangan hama utama. Kandungan gosipol dan trikoma yang terdapat pada biji boll dan mahkota dapat menahan serangan hama yang ingin merusak boll tersebut. Kapas yang memiliki rentan terhadap serangan hama terdapat pada plasma nutfah Chris 670 ini diduga kandungan gosipol rendah, Crish 670 sehingga buah tersebut rusak oleh hama dengan struktur buah pendek dan kapas yang memiliki ketahan terdapat kerusakan boll dimiliki oleh plasma nutfah SA 2465 dan Marvin 425 dengan struktur buah yang panjang (Tabel 2).
Diduga kerusakan disebabkan bapak pucung (Dysdercus cingulatus), Bapak pucung memiliki mulut tipe menusuk dan menghisab. Pada buah kapas yang akan membuka, serangan Bapak Pucung (Dysdercus cingulatus) menyebabkan serat kapas menjadi berwarna coklat kekuningan dan bahkan buah menjadi busuk sehingga dapat menurun dalam produksi buah kapas siap panen (Hidayati dan Nurrohmah, 2017). Hama ini berkembang biak pada saat kelembaban tinggi jika kondisi kering maka telur tidak menetes (Pracaya, 2008). Ulat buah juga dapat menyebabkan boll tersebut rusak akibat dilubangi.

Tabel 2. Indeks kerusakan boll pada Fase Generatif

\begin{tabular}{ll}
\hline Perlakuan & Rataan \\
\hline FDH 834 & $1,2^{\mathrm{a}}$ \\
Marvin 425 & $1,2^{\mathrm{a}}$ \\
Kanesia 11 & $1,3^{\mathrm{ab}}$ \\
Chris 670 & $2,2^{\mathrm{abc}}$ \\
Kanesia 14 & $2,2^{\mathrm{abc}}$ \\
Chris 324 & $2,2^{\mathrm{abc}}$ \\
Chris 665 & $2,3^{\mathrm{abc}}$ \\
SA 2467 & $2,4^{\mathrm{abc}}$ \\
Chris 668 & $2,5^{\mathrm{abc}}$ \\
Kanesia 18 & $2,7^{\mathrm{abc}}$ \\
Kanesia 19 & $2,8^{\mathrm{bc}}$ \\
Chris 664 & $2,8^{\mathrm{bc}}$ \\
SA 2465 & $2,9^{\mathrm{cd}}$ \\
Chris 669 & $3,0^{\mathrm{cd}}$ \\
Kanesia 12 & $3,1^{\mathrm{cd}}$ \\
Kanesia 16 & $3,1^{\mathrm{cd}}$ \\
Chris 667 & $3,2^{\mathrm{cd}}$ \\
Kanesia 20 & $3,2^{\mathrm{cd}}$ \\
Kanesia 17 & $3,4^{\mathrm{cd}}$ \\
Kanesia 15 & $3,5^{\mathrm{cd}}$ \\
Kanesia 13 & $3,5^{\mathrm{cd}}$ \\
Chris 666 & $4,4^{\mathrm{d}}$ \\
\hline
\end{tabular}

Keterangan: Angka pada kolom yang diikuti dengan huruf yang sama menunjukkan tidak berbeda nyata (non significant) pada Uji BNT 5\%

\section{Bobot Boll Fase Generatif}

Bobot boll sangat mempengaruhi hasil yang diperoleh saat menanam kapas untuk mengetahui jumlah bobot yang diperoleh saat memanen kapas. Tetapi banyak varietas kapas yang terserang hama saat fase generatif pembentukan boll, sangat mempengaruhi bobot, saat memasuki panen hama yang paling banyak di bagian boll yaitu bapak pucuk. Hama tersebut akan menurunkan kualitas dan berat boll tersebut karena akan menimbulkan bercak hitam pada boll tersebut. kapas yang memiliki berat boll.g-1 yang paling baik terdapat pada plasma nutfah kanesia 17 sedangkan berat boll.g-1 yang paling rendah dimiliki oleh plasma nutfah SA 2465 (Tabel 3). Ketersedian unsur hara $P$ sangat dibutuhkan dalam pembentukan buah. Jika unsur $P$ tidak tersedia dengan cukup maka aliran karbohidrat terhambat atau terbatas dapat mempengaruhi jumlah buah dan bobot buah kapas (Amiroh, 2009). Hal ini dapat mengindentifikasikan kapas yang yang tidak memiliki berat yang seragam karena ketersediaan hara 
terbatas dari masing-masing tanaman. Kondisi iklim juga menentukan berat boll pada tanaman kapas apabila musim kering pada saat berbuah maka bobot kapas akan berkurang. Waktu yang paling tepat menanam kapas yaitu musim hujan agar pada saat panen kapas sudah memasuki kemusim kemarau sehingga akan menghasilkan kualitas kapas yang paling baik dan berwarna putih bersih.Selain itu juga cekaman air dan cahaya matahari dapat mempengaruhi bobot kapas. Curah hujan musiman dapat mengakibatkan spesies melimpah dalam merusak buah kapas. Beberapa spesies akan melimpah jika curah hujan rendah walaupun ketersedian tanaman inangnya rendah. Curah yang tinggi dapat mengakibatkan kematian secara langsung pada serangga dikarenakan perkembangan patogen serangga (Mavi dan Tuper, 2004).

Tabel 3. Indeks bobot boll pada fase generatif

\begin{tabular}{|c|c|}
\hline Perlakuan & Rataan \\
\hline FDH 834 & $2,20^{a}$ \\
\hline Marvin 425 & $2,35^{a b}$ \\
\hline Kanesia 11 & $2,35^{a b}$ \\
\hline Chris 670 & $2,55^{a b}$ \\
\hline Kanesia 14 & $2,60 a b c$ \\
\hline Chris 324 & $2,95 \mathrm{abcd}$ \\
\hline Chris 665 & 3,20 abcde \\
\hline SA 2467 & 3,40 bcdef \\
\hline Chris 668 & 3,40 bcdef \\
\hline Kanesia 18 & 3,45 bcdef \\
\hline Kanesia 19 & 3,70 cdef \\
\hline Chris 664 & 3,75 def \\
\hline SA 2465 & 3,85 def \\
\hline Chris 669 & 3,85 def \\
\hline Kanesia 12 & 3,90 def \\
\hline Kanesia 16 & 3,90 def \\
\hline Chris 667 & 4,00 def \\
\hline Kanesia 20 & 4,00 def \\
\hline Kanesia 17 & 4,15 ef \\
\hline Kanesia 15 & 4,15 ef \\
\hline Kanesia 13 & $4,40^{f}$ \\
\hline Chris 666 & $4,50^{f}$ \\
\hline
\end{tabular}

Keterangan: Angka pada kolom yang diikuti dengan huruf yang sama menunjukkan tidak berbeda nyata (non significant) pada Uji BNT 5\%

\section{KESIMPULAN}

Plasma nutfah kapas FDH 834 resisten terhadap kerusakan daun tetapi rentan terhadap kerusakan batang pada fase generatif dan plasma nutfah kapas SA 2465 dan Marvin 425 resisten terhadap hama penggerek boll. Pada kanesia 17 yang memiliki bobot boll yang tertinggi.

\section{DAFTAR PUSTAKA}

Amiroh, A. (2009). Pemakaian Jenis Pupuk Terhadap

Pertumbuhan dan Produksi Kapas Berbiji Pala
Tumpangsari Kedelai (Glycium max). 1(1): 30-36.

Dewi, E. S. (2014). Aspek Agronomi Tanaman Kapas. Jakarta timur.

Fahn, S. (1990). Plant anatomy. 4 th Ed. Butter worthheinemann 2(3): 165-72.

Hagenbucher, S., Eisenring, M., Meissle, M., \& Romeis, J. (2017). Interaction of Transgenic and Natural Insect Resistance Mechanisms against Spodoptera littoralis in Cotton. Pest Management Science. 73(8): 1670-1678.

Harsanti, L. (2016). Pengamatan Sifat Agronomi, Mutu Serat dan Hama Penyakit Galur Mutan Harapan Kapas (Gossypium hirsutum L.) di Citayam Bogor. 12(2): 123-132.

Hidayati, N., \& Nurrohmah, S. H. (2017). Inventarisasi Serangga pada Kebun Koleksi Klon Kaliandra (Calliandra calothyrsus) yang Berpotensi Sebagai Hama. In Prosiding SNPBS. URL:http: //hdl.Handle.Net/11617/9316. Diakses pada 8 November 2019.

Johnson, J., Macdonald, S., Meyer, L., Norrington, B., \& Skelly, C. (2014). Agricultural Outlook Forum The World and United States Cotton Outlook.URL:http://www.usda.gov/oce/forum/201 4_Speeches/Cotton.pdf. Diakses pada 8 November 2019.

Kasno, A., Trustinah, \& Rahmiana, A. (2015). Seleksi Galur Kacang Tanah Adaptif Pada Lahan Kering Masam. Jurnal Penelitian Pertanian Tanaman Pangan 32(1): 16-24.

Kementerian Pertanian. (2014). Kementerian Pertanian. $\quad$ URL: http://aplikasi.pertanian.go.id/bdsp/newkom.asp. Diakses pada 8 November 2019.

Mavi, H. S., \& Tuper, G. J. (2004). Agrometeorogi principles and applications of climate studies in agriculture. Food products press, New York.

Natasa, A. A., Elza, Z., \& Adiwirman. (2016). Pertumbuhan dan Kandungan Serat beberapa Varietas Kenaf (Hibiscus cannabinus L.). JOM Faperta. 71(1): 233-238.

Pracaya. (1999). Pengendalian Hama Dan Penyakit Tanaman. Penebar Swadaya, Jakarta.

Pracaya. (2008) .Pengendalian Hama Dan Penyakit Tanaman Organik. Kanisius, Yogyakarta.

Sahid, M. (2001). Budi Daya Kapas Lahan Tadah Hujan. Penelitian Tembakau dan Serat, Hal. 109-118.

Tengkano, W., \& Suharsono. (2005). Uat grayak Spodoptera litura Fabricius (Lepidoptera: Noctuidae) pada Tanaman Kedelai dan Pengendalianya. Buletin Palawija (10): 43-52. 